\title{
Fluorescent Probe Studies of Sodium/Sugar Cotransport and Membrane Potential Changes in Isolated Chicken Enterocytes
}

\author{
Yoshito KINOSHITA and Akihiko IRIMAJIRI \\ Department of Physiology, Kochi Medical School, \\ Nankoku, Kochi, 781-51 Japan
}

\begin{abstract}
The fluoroprobe technique using a potential-sensitive dye, diS$\mathrm{C}_{3}(5)$, was applied to isolated enterocytes in order to correlate membrane potential changes with $\mathrm{Na}^{+}$/sugar cotransport. Cells were prepared from the chicken small intestine by enzymatic (Dispase) treatment combined with mechanical agitation. In the presence of $\mathrm{Na}^{+}$, addition of D-glucose $(2 \mathrm{mM})$ to the suspension of cells doped with the dye $(1.8 \mu \mathrm{M})$ gave rise to $\mathrm{Na}^{+}$-dependent increases in fluorescence indicative of depolarization of the cell membrane potential. The $\mathrm{pH}$ optimum for this response was ca. 7.3. Similar but smaller fluorescence increases were also evoked by Dgalactose, $\alpha$-methyl-D-glucoside, and 3-O-methyl-D-glucose, all known to be actively accumulated by enterocytes in a $\mathrm{Na}^{+}$-dependent fashion. These monosaccharide-evoked fluorescence changes were suppressed by lowering the extracellular $\mathrm{Na}^{+}$concentration or by phlorizin. Monosaccharides with no reported $\mathrm{Na}^{+}$requirement induced no such fluorescence responses. A disaccharide, maltose, elicited a smaller fluorescence increase which also was $\mathrm{Na}^{+}$dependent and phlorizin inhibitable; this was interpreted as due to a possible supply of D-glucose by the membranebound disaccharidase systems. No change was observed with lactose, sucrose, or trehalose, however. The glucose-evoked fluorescence changes correlatable with depolarization were also confirmed using another carbocyanine, diO- $\mathrm{C}_{5}(3)$. These results demonstrate that fluorescence from diS$\mathrm{C}_{3}(5)$ or diO- $\mathrm{C}_{5}(3)$ can be a good measure for cotransport-associated membrane potential changes in isolated intestinal epithelial cells.
\end{abstract}

Key words: $\mathrm{Na}^{+} /$sugar cotransport, fluorescent probe, membrane potential, phlorizin, chicken enterocytes.

It is well established that $\mathrm{Na}^{+}$-dependent sugar accumulation in the intestinal epithelium is accompanied by concomitant changes in the cell membrane potential (for reviews, see e.g. Kiмmich, 1981; Schultz, 1981). The first indication of this

Received for publication May 17, 1988 
cotransport-associated electrical phenomenon was obtained from measurements of transmural potential difference and short-circuit current (CLARKSON et al., 1961; BARRY et al., 1964; SCHUlTZ and ZALUSKY, 1964; LyON and CRANE, 1966; Hoshi and Komatsu, 1968), and then confirmed by more recent experiments in which the epithelial cells were impaled from the mucosal side with a microelectrode to record sugar-evoked changes in the intracellular potential (Rose and SCHULTZ, 1971; White and Armstrong, 1971; Frizzell and Schultz, 1972; OKada et al., 1977a). However, the interpretation of membrane potentials from intact tissues was by no means straightforward because the nature of the recorded potentials had more or less been modified by the presence of paracellular shunt pathways, or the "leaky" tight junctions, electrically shunting to a variable extent between the mucosal and serosal extracellular environments. To extract the "true" membrane potentials, therefore, some sophisticated analyses based on equivalent-circuit models were required (Frizzell and Schultz, 1972; OKada et al., 1977a, b; Schultz, 1979).

Although direct monitoring of membrane potentials free from these complications is desirable, the application of the conventional microelectrode technique to isolated enterocytes has been hampered by their small size and also by their vulnerability to the isolation as well as impalement maneuvers employed. So far, only a few investigations dealing with fragmented intestinal villi in culture have been reported (TsuchIYA et al., 1980; TsuCHIYA and OKADA, 1982). In an attempt to circumvent these technical difficulties we undertook a fluoroprobe analysis with special emphasis put on the correlation between sugar transport and associated membrane potential changes in isolated enterocytes in suspension.

Optical methods using potential-sensitive dyes have been successfully developed in the last decade (for reviews, see COHEN and SALZBERG, 1978; WAGGONER, 1979; FREEDMAN and LARIS, 1981), and have been extensively applied to intestinal as well as renal membranes in vitro, as recently reviewed by WRIGHT (1984). However, the scope of their applications has been limited mostly to the membrane vesicle level, skipping over the whole-cell level where much information could be gained if it were ever accessible by a reasonable means. In the present study we extend the applicability of the potential-probing optical method to isolated intestinal cells and demonstrate that fluorescence changes indicative of depolarization of membrane potentials are closely correlated with the cells' capability for active sugar uptake.

\section{MATERIALS AND METHODS}

Materials. Day-old White Leghorn chickens from a local poulterer were raised in the animal facility with free access to food and water until sacrificed. The sources of materials used in this work were as follows: diS- $\mathrm{C}_{3}(5)$ and diO- $\mathrm{C}_{5}(3)$ from Nippon Kankoh-Shikiso Kenkyusho, Okayama; Dispase from Godo Shusei, Tokyo; D-glucose, L-glucose, D-galactose, 3-O-methyl-D-glucose, D-fructose, lactose, maltose, sucrose, L-alanine, L-glutamine, $\beta$-hydroxybutyrate, and choline $(50 \%$, aqueous solution) from Nacalai Tesque, Kyoto; $\alpha$-methyl-D-glucoside 
from Wako Pure Chemical Industries, Osaka; and 2-deoxy-D-glucose (Grade III), D-mannose, trehalose, phlorizin, and phenylmethylsulfonylfluoride from Sigma, St. Louis, MO, U.S.A. Other chemicals were of highest available quality from commercial sources. Phlorizin was recrystallized from a hot aqueous solution. Choline was titrated with $\mathrm{H}_{2} \mathrm{SO}_{4}$ to $\mathrm{pH} 7.0$ and treated with charcoal to obtain a colorless solution of choline sulfate whose concentration was determined osmometrically.

Thin-layer chromatography and purification of sugars. Purity of test sugars as received was examined by thin-layer chromatography using Silica Gel 60 F254 (Merck, Darmstadt, FRG) and an $n$-butanol/pyridine/acetic acid/water (10:6:1:3, by volume) solvent system. Spots were located with an orcinol reagent. As the commercial lots of 2-deoxy-D-glucose were contaminated by D-glucose, purification by column chromatography was made using Avicel (Asahikasei, Tokyo) with the same solvent system as in the thin-layer chromatography. Determination of $D$ glucose as contaminant was also made colorimetrically by the hexokinase/glucose6-phosphate dehydrogenase method (Gluco-quant, Boehringer, Mannheim, FRG) except for the case of 2-deoxy-D-glucose which could not be discriminated from Dglucose by this method.

Solutions. The compositions of the media used were as follows (in $\mathrm{mm}$ ): medium A: $120 \mathrm{NaCl}, 5 \mathrm{KCl}, 22.5$ Tris- $\mathrm{HCl}$ (pH 7.3), 0.1 phenylmethylsulfonylfluoride (a protease inhibitor); medium B: Dispase (1,000 protease units $/ \mathrm{ml}$ ) and bovine serum albumin $(2 \mathrm{mg} / \mathrm{ml})$ dissolved in medium $\mathrm{A}$; medium $\mathrm{C}$ : $60 \mathrm{Na}_{2} \mathrm{SO}_{4}, 2.5$ $\mathrm{K}_{2} \mathrm{SO}_{4}, 1 \mathrm{CaSO}_{4}, 1 \mathrm{MgSO}_{4}, 20$ Tris- $\mathrm{H}_{2} \mathrm{SO}_{4}(\mathrm{pH} \mathrm{7.3})$, and an appropriate amount of choline sulfate to adjust the osmolality. In addition to the above recipe, medium $\mathrm{C}$ was freshly supplemented, for the purpose of energizing the cells, with $10 \mathrm{~mm} \mathrm{D}$ mannose, $2.5 \mathrm{mM}$ L-glutamine, and $0.5 \mathrm{mM} \beta$-hydroxybutyrate ( $\mathrm{Na}$ salt), as recommended by Кіммсн and RandLes (1979), and its final osmolality as checked by the freezing-point depression method was 285-290 mOsm. Test media of varying $\mathrm{Na}^{+}$ concentrations were prepared by equiosmolal replacement of $\mathrm{Na}_{2} \mathrm{SO}_{4}$ with choline sulfate in medium $\mathrm{C}$.

Preparation of enterocytes. Usually a 10- to 25-day-old chicken was sacrificed by decapitation for each preparation. An immediate preombilic segment (about $12 \mathrm{~cm}$ ) distal to the duodenum was excised from the upper small intestine, and the luminal content was flushed out with medium $\mathrm{A}$. The intestinal segment was everted over a glass rod $(5-6 \mathrm{~mm}$ by $15 \mathrm{~cm})$, transferred to a test tube filled with medium $A$, and subjected to mechanical/manual vortexing to remove debris from the mucosal surface. After a rinse with medium A, the tissue as supported by the glass rod was incubated in a test tube $(12 \mathrm{~mm}$ by $14 \mathrm{~cm})$ of medium $\mathrm{B}$ at $37^{\circ} \mathrm{C}$ for $20-30 \mathrm{~min}$. The treated segment was transferred to a test tube of medium $\mathrm{C}$ (ice-cold) and the rod was finger twisted several times so as to dislodge the loosened mucosal cells. The suspension of cells thus obtained was passed through two layers of nylon gauze to remove large cell clumps and debris. After washing twice with medium $C$ (ice-cold) by flash centrifugation at $800 \times g$, the cells were resuspended in the same medium to 
a concentration of $5 \times 10^{6}$ "viable" cells $/ \mathrm{ml}$ and kept on ice until use. The whole procedure described was completed within $1 \mathrm{~h}$ after sacrifice.

Cell viability was estimated by a dye exclusion method using $0.04 \%$ erythrosine B (Phillips, 1973). While parallel determinations using trypan blue gave 5-10\% higher counts for unstainable cells, we preferred erythrosine $\mathrm{B}$ for its relative ease in the stainability assessment. Cell preparations with viability below $70 \%$ were discarded.

Fluorescence measurements. Fluorescence was measured with a Shimadzu RF-503A difference (split-beam) spectrofluorometer equipped with thermostated cell holders and matched stirring devices. This type of fluorometer was versatile in that the difference mode of operation enabled a real-time detection of difference fluorescence between the sample and reference cuvettes. Normal-mode recordings to register the absolute intensity were made by simply interrupting one of the two light paths. Excitation and emission wavelengths were respectively set at 620 and $670 \mathrm{~nm}$ (band pass, $5 \mathrm{~nm}$ ) for diS- $\mathrm{C}_{3}(5)$ or at 460 and $510 \mathrm{~nm}$ (band pass, $5 \mathrm{~nm}$ ) for diO- $\mathrm{C}_{5}(3)$. Emission spectra of $\operatorname{diS}-\mathrm{C}_{3}(5)$ were recorded with the same setting as above except for the emission wavelength. All measurements including preconditioning of test cells were performed at $30^{\circ} \mathrm{C}$.

As will be detailed in RESULTS AND DISCUSSION, the cells once isolated and/or exposed to the cyanine dyes gradually deteriorated as time elapsed, so that for successful measurements it was essential to adopt a well-planned protocol. Our standard procedure was as follows: A $0.2-\mathrm{ml}$ aliquot of the stock cell suspension which, for the purpose of energization, had been preincubated in medium $\mathrm{C}$ for $10 \mathrm{~min}$ at $30^{\circ} \mathrm{C}$ was mixed with $4.8 \mathrm{ml}$ of prewarmed test medium (i.e., medium $\mathrm{C}$ or its modifications), to which was subsequently added $20 \mu \mathrm{l}$ of an ethanolic solution of diS- $\mathrm{C}_{3}(5)$ to make the final dye concentration $1.8 \mu \mathrm{M}$ (ethanol $\left.<0.4 \%, \mathrm{v} / \mathrm{v}\right)$. From this, $2 \mathrm{ml}$ each was taken out into two paired cuvettes that were then placed in an air oven $\left(30^{\circ} \mathrm{C}\right)$, and stirring was started. After setting the cuvettes in the fluorometer, test solutes were added to the sample side at the set times, and evoked fluorescence changes were recorded in the difference mode. Additions were usually made in less than $10 \mu \mathrm{l}$; otherwise, an equal volume of water was added to the reference side to counterbalance the dilution effect. Under the present experimental conditions, the final cell concentration $\left(2 \times 10^{5}\right.$ viable cells $\left./ \mathrm{ml}\right)$ gave a cytocrit of about $0.1 \%$, and therefore, changes, if any, in the bulk concentration of the dye due to cell swelling or shrinking itself were considered to be negligible. No spectral shifts were observed following the addition of test sugars.

Miscellaneous. Protein was determined by a HARTREE (1972) modification of the Lowry method with bovine serum albumin as standard. ATP was determined by the luciferin-luciferase/internal-standard method using an ATP photometer (Monolight 401, Analytical Luminescence Lab., San Diego, CA, U.S.A.). Lactate was assayed by using a commercial kit (F-kit L-lactic acid, Boehringer). 


\section{RESULTS AND DISCUSSION}

\section{Isolated cells}

Figure 1 shows typical Nomarski micrographs of enterocytes prepared by the combined enzymatic/agitative method and finally suspended in medium $\mathrm{C}$. The cells were generally well dispersed but clumps were also observed, in gross resemblance to those of Kimmich (1975). The majority of cells were identified as columnar epithelial cells having well-preserved brush-border profiles. Cell yield varied from experiment to experiment, ranging over $5-20 \mathrm{mg}$ of cell protein per 12-cm segment.

Viability was usually better than $75 \%$ (erythrosine B exclusion) or $85 \%$ (trypan blue exclusion). Both the ATP content $(5-6 \mathrm{nmol} / \mathrm{mg}$ cell protein) determined after incubation in medium $\mathrm{C}$ for $10 \mathrm{~min}$ at $30 \mathrm{C}$ and the lactate production rate $(750 \mathrm{nmol} / \mathrm{h}$ per $\mathrm{mg}$ cell protein) assayed over an incubation period of $20 \mathrm{~min}$ were comparable to previous reports on isolated chicken enterocytes (КIмMICH, 1975; WATFORD et al., 1979), indicating a well-retained metabolic activity for the present cells. Dispase as the dissociation agent was successfully applied to the preparation of rabbit enterocytes (TANIGUCHI et al., 1977), and our results also have confirmed that the dispase method can be an alternative to other methods using, for example, hyaluronidase (Kimmich, 1975; CheEseman and Devlin, 1985).

Glucose-evoked fuorescence changes: $d i S-C_{3}(5)$

Figure 2a illustrates difference-mode fluorescence changes evoked by addition of D-glucose to a suspension of enterocytes. The sugar $(2 \mathrm{~mm})$ added to the sample side elicited an increase in fluorescence, and a symmetrical addition to the reference side reversed the signal down to the baseline, as expected. The fact that the time course of the latter response virtually traced a mirror image of the initial one appeared to guarantee that, under the condition of constant stirring at $30^{\circ} \mathrm{C}$, the

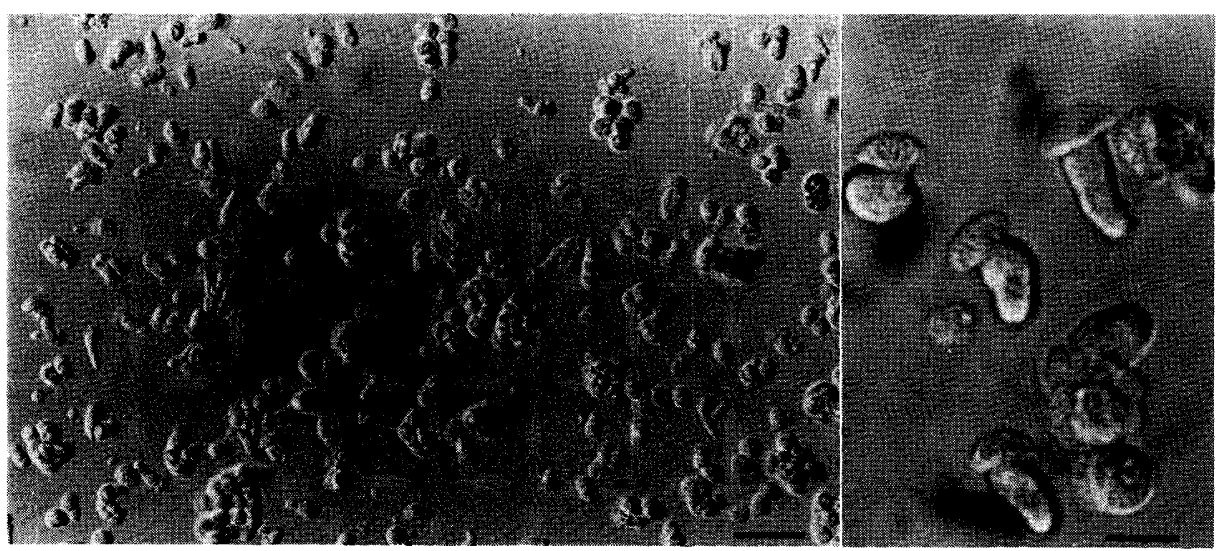

Fig. 1. Differential interference (Nomarski) micrographs of isolated chicken enterocytes suspended in medium C (see text). Scale bars: left, $40 \mu \mathrm{m}$; right, $10 \mu \mathrm{m}$. 

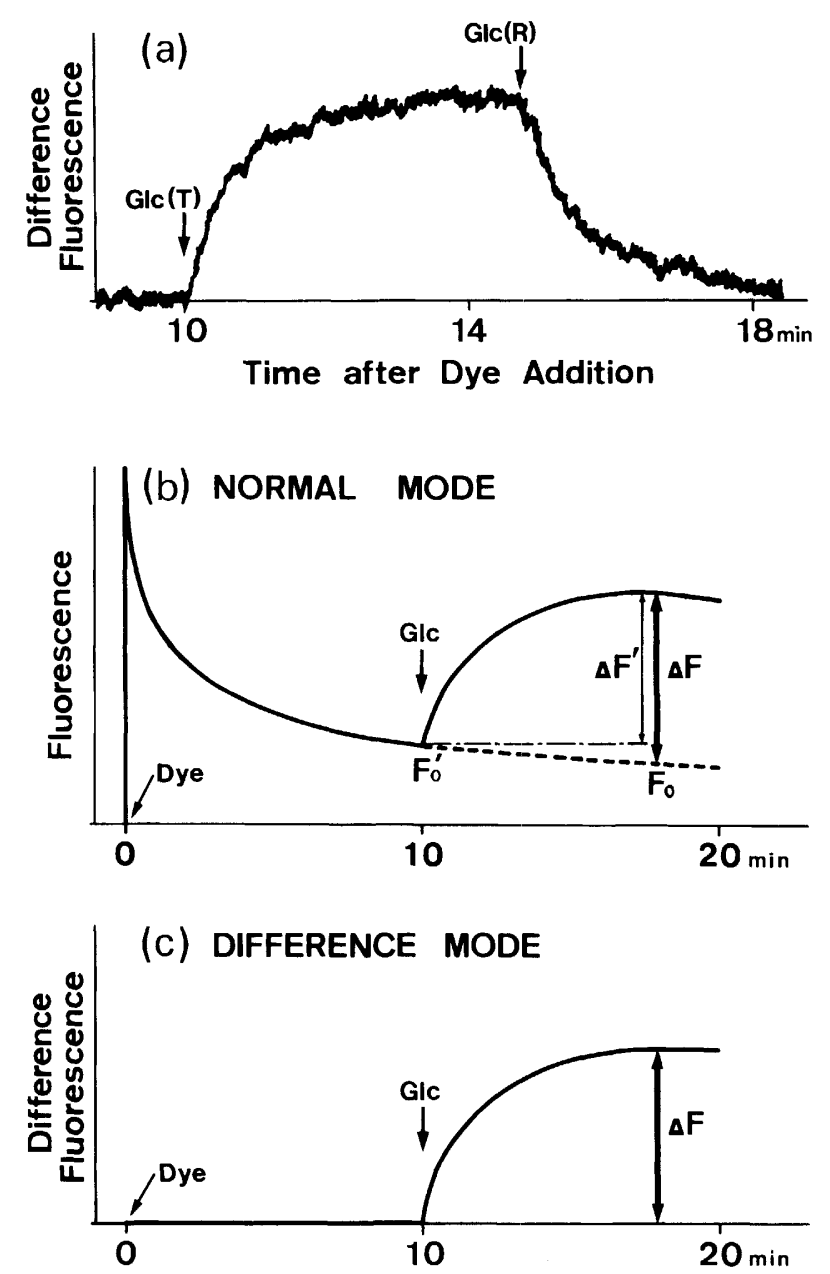

Fig. 2. Illustration of the difference-mode recordings of diS- $\mathrm{C}_{3}(5)$ fluorescence. (a) Time course of difference (sample minus reference) fluorescence. Arrows indicate the additions of $2 \mathrm{~mm}$ D-glucose to the test $(T)$ and reference $(R)$ cuvettes each containing $4 \times 10^{5}$ viable cells per $2 \mathrm{ml}$ of suspension. Medium C (see text). Dye, $1.8 \mu \mathrm{M}$. Temperature, $30^{\circ} \mathrm{C}$. Curves in (b) and (c), schematics of normal and difference modes of recording. Arrows, additions of dye and glucose. Symbols, as defined in text.

cells maintained their activity for at least $15 \mathrm{~min}$ (see also Fig. 3) and further that symmetry between the two (sample and reference) cell suspensions was excellent. Note also that the baseline was stabilized well within $10 \mathrm{~min}$ after the dye addition. This latter fact was particularly advantageous, or even mandatory, both for preventing cell deterioration due to prolonged waiting otherwise required and for expediting as many measurements as possible on a single batch of cells within a 
limited period of time.

Figure $2 b$ and $c$ schematically compares the two modes of operation, where the normal mode refers to conventional fluorometry using one cuvette in the singlebeam optics. Apparently, the difference-mode operation is capable of simultaneous, hence more accurate, determinations of both $\Delta F$ (=solute-evoked change in fluorescence) and $F_{0}$ (=basal fluorescence level to be observed with no solutes added); the latter has so far been inaccessible in the normal-mode operation and so conventionally approximated by $F_{0}{ }^{\prime}$, the fluorescence level prior to the solute addition (Fig. 2b). Accordingly, we express fluorometric data, wherever pertinent, in terms of relative fluorescence changes $(\mathscr{F})$ defined by:

$$
\mathscr{F}=\Delta F / F_{0}
$$

where expectedly $F_{0} \neq F_{0}$ '.

When recorded in the normal mode, the downward shift of the baseline usually lasted for more than $20 \mathrm{~min}$ following the dye addition, as schematically shown in Fig. 2b. It was therefore necessary to examine what differences would ensue between an early addition of test solutes and a later one in the resulting $\mathscr{F}$-values. The result of such experiments ("time" effect) is summarized in Fig. 3. Here, individual data points refer to average responses from five separate experiments, in each of which a single batch of cells was used and data for the shown time points were normalized to the response for the 10 -min point which was taken as $100 \%$. The averaged responses to the same $2 \mathrm{~mm}$ D-glucose were highest when the addition was made $5 \mathrm{~min}$ later following the dye, sustained a near $100 \%$ level for a further $10 \mathrm{~min}$, and thereafter declined rather markedly. Responses at or before the 5-min point were more variable because of as yet unstabilized baselines. Therefore, the standard protocol

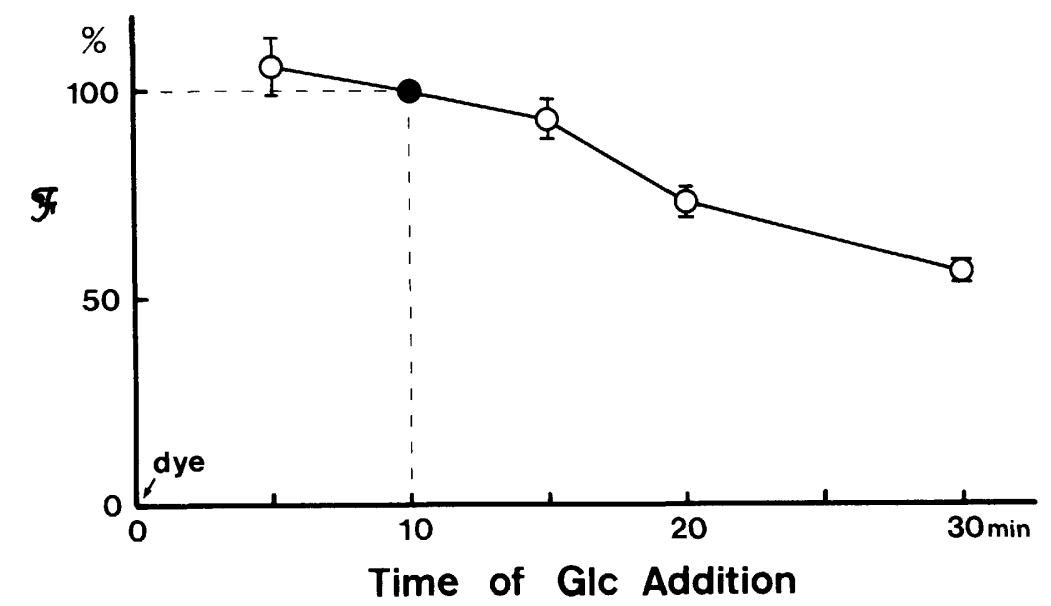

Fig. 3. Changes in the cells' response to the sáme but staggered additions of $2 \mathrm{~mm}$ Dglucose. Data from 5 separate series of experiments are normalized to the 10-min points for each and are expressed as mean \pm S.E.M. 
was chosen such that test solutes were added exactly at $10 \mathrm{~min}$ after the onset of cells' exposure to diS- $\mathrm{C}_{3}(5)$, throughout the experiments presented below.

\section{Fluorescence responses: diO- $C_{5}(3)$}

Figure 4 shows a typical experiment using another cyanine dye, diO- $\mathrm{C}_{5}(3)$, in place of diS- $\mathrm{C}_{3}(5)$. This carbocyanine as a potential-sensitive indicator is known to behave differently from diS- $\mathrm{C}_{3}(5)$ in that the direction of fluorescence changes to the same degree of depolarization reverses depending on the dye concentration employed: an increase in fluorescence for the micromolar range of diO- $\mathrm{C}_{5}(3)$ and a decrease for the submicromolar range (Sims et al., 1974). If the responses observed with diS- $\mathrm{C}_{3}(5)$ ever reflected membrane potential changes, particularly "depolarization," in the isolated enterocytes, then the same additions of D-glucose should lead to reversal of fluorescence changes at a critical concentration of the probe, diO$\mathrm{C}_{5}(3)$. This was the case, as expected, and the reversal concentration was about $0.4 \mu \mathrm{M}$ in good agreement with Sims et al. (1974). Thus, tenable support was obtained in favor of a close correlation between the sugar-evoked fluorescence increases and the depolarization of enterocytes' membrane potentials.*

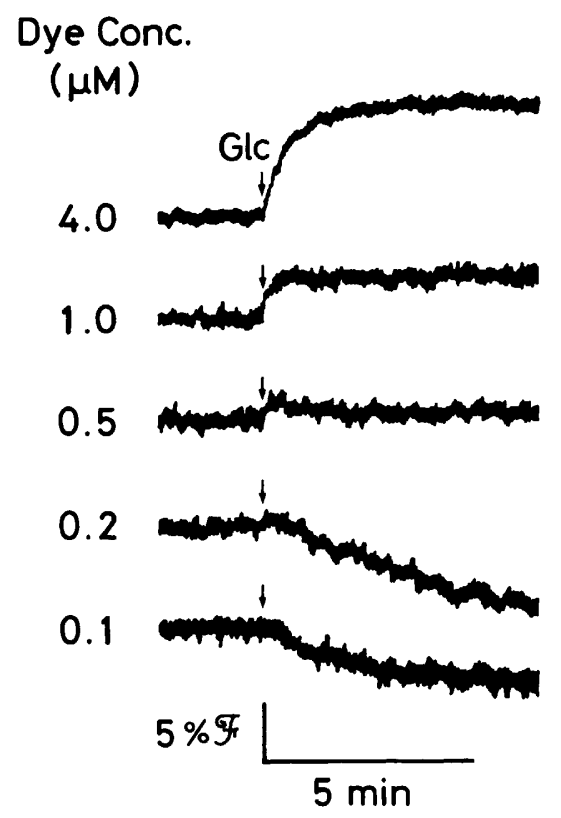

Fig. 4. Fluorescence responses of diO- $\mathrm{C}_{5}(3)$-doped cells to $2 \mathrm{~mm}$ D-glucose as a function of dye concentration. $2 \times 10^{5}$ viable cells $/ \mathrm{ml}$. Medium C (see text). $30^{\circ} \mathrm{C}$.

* In a preliminary experiment, we examined the behavior of relative fluorescence $\left(F / F_{0}\right)$, in the presence of $1 \mu \mathrm{M}$ valinomycin, as a function of medium $\mathrm{K}^{+}$concentration $\left(\left[\mathrm{K}^{+}\right]_{0}\right)$. Here, $F_{0}$ and $F$ are respectively the fluorescence levels attained before and after cell addition. Over the range of $\left[\mathrm{K}^{+}\right]_{\mathrm{o}}$ from 


\section{Effect of $p H$}

Medium pH may affect not only $\Delta F$, the sugar-evoked change, but also $F_{0}$, the basal fluorescence level of $\operatorname{diS}_{-} \mathrm{C}_{3}(5)$, by altering its partition across the cell membrane (HLADKY and RINK, 1976); so the $\mathrm{pH}$ dependence of both parameters for $2 \mathrm{~mm}$ D-glucose was examined, with the results as shown in Fig. 5A. Values of $\mathscr{F}$

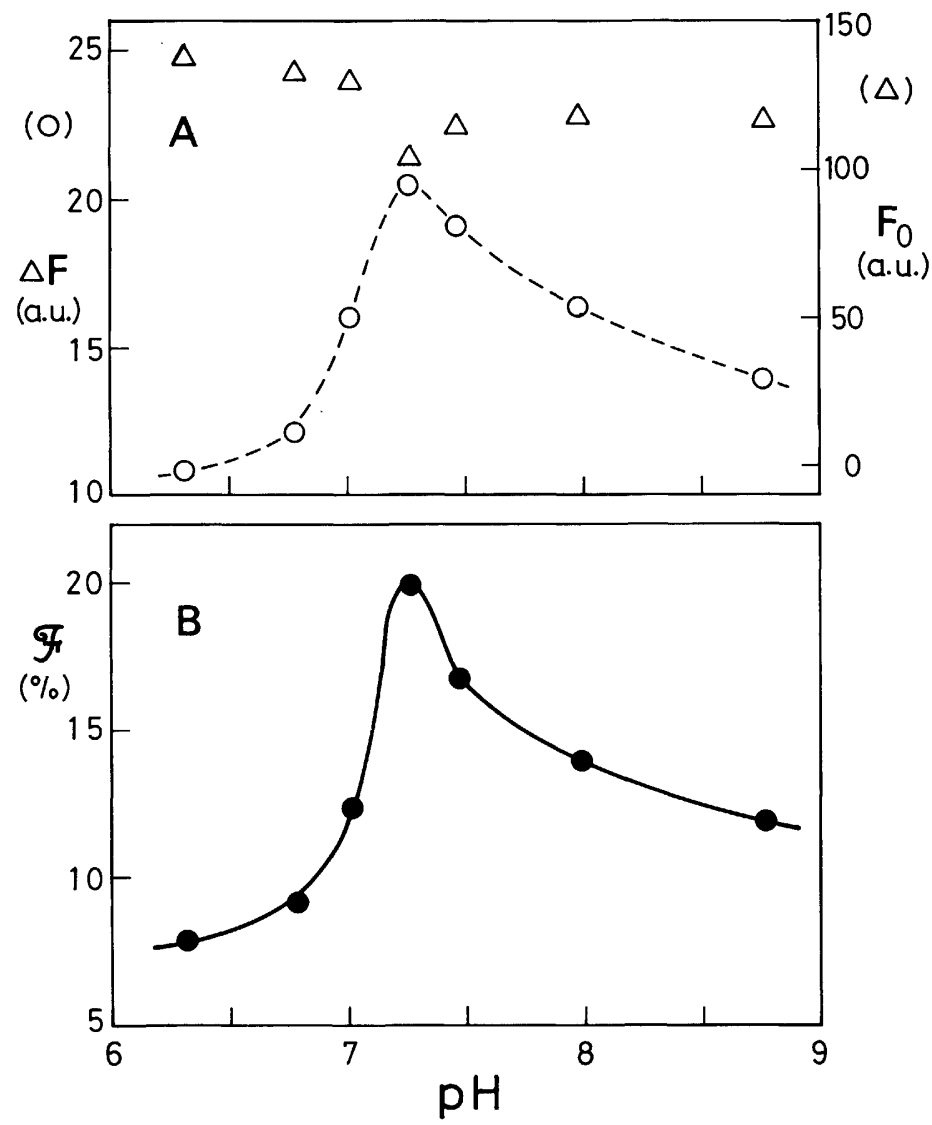

Fig. 5. D-Glucose (2 $\mathrm{mm})$-evoked fluorescence increase $(\mathscr{F})$ as a function of medium $\mathrm{pH}$. The basal solution for $\mathrm{pH} 7.3$ was medium $\mathrm{C}$ (see text), to which was added either choline base for the range $\mathrm{pH}>7.3$ or $\mathrm{H}_{2} \mathrm{SO}_{4}$ for the range $\mathrm{pH}<7.3$. Ionic strength increments due to these additions were within $4 \%$ relative to the strength for medium $\mathrm{C}$.

10 to $120 \mathrm{~mm}, F / F_{0}$ increased almost linearly with $\log \left[\mathrm{K}^{+}\right]_{\mathrm{o}}$, giving a slope of about 0.12 per decade change of $\left[\mathrm{K}^{+}\right]_{0}$. This same slope was also obtained in the absence of the $\mathrm{K}^{+}$ionophore in the $\left[\mathrm{K}^{+}\right]_{0}$ range of $60-120 \mathrm{~mm}$. This fact strongly indicates that increases in the diS- $\mathrm{C}_{3}(5)$ fluorescence from enterocyte suspensions did report "depolarization," not "hyperpolarization," of the cell membrane potential. 
$\left(=\Delta F / F_{0}\right)$ derived from Fig. 5A are plotted in Fig. 5B. As seen, $F_{0}$ decreased as a function of $\mathrm{pH}$ within the $\mathrm{pH}$ range 6-8; a similar $\mathrm{pH}$ dependence of $F_{0}$ has been reported by HOFFMAN and LARIS (1974) for a suspension of red cells containing a carbocyanine dye. Therefore, the use of $\mathscr{F}$ defined above proved pertinent also in
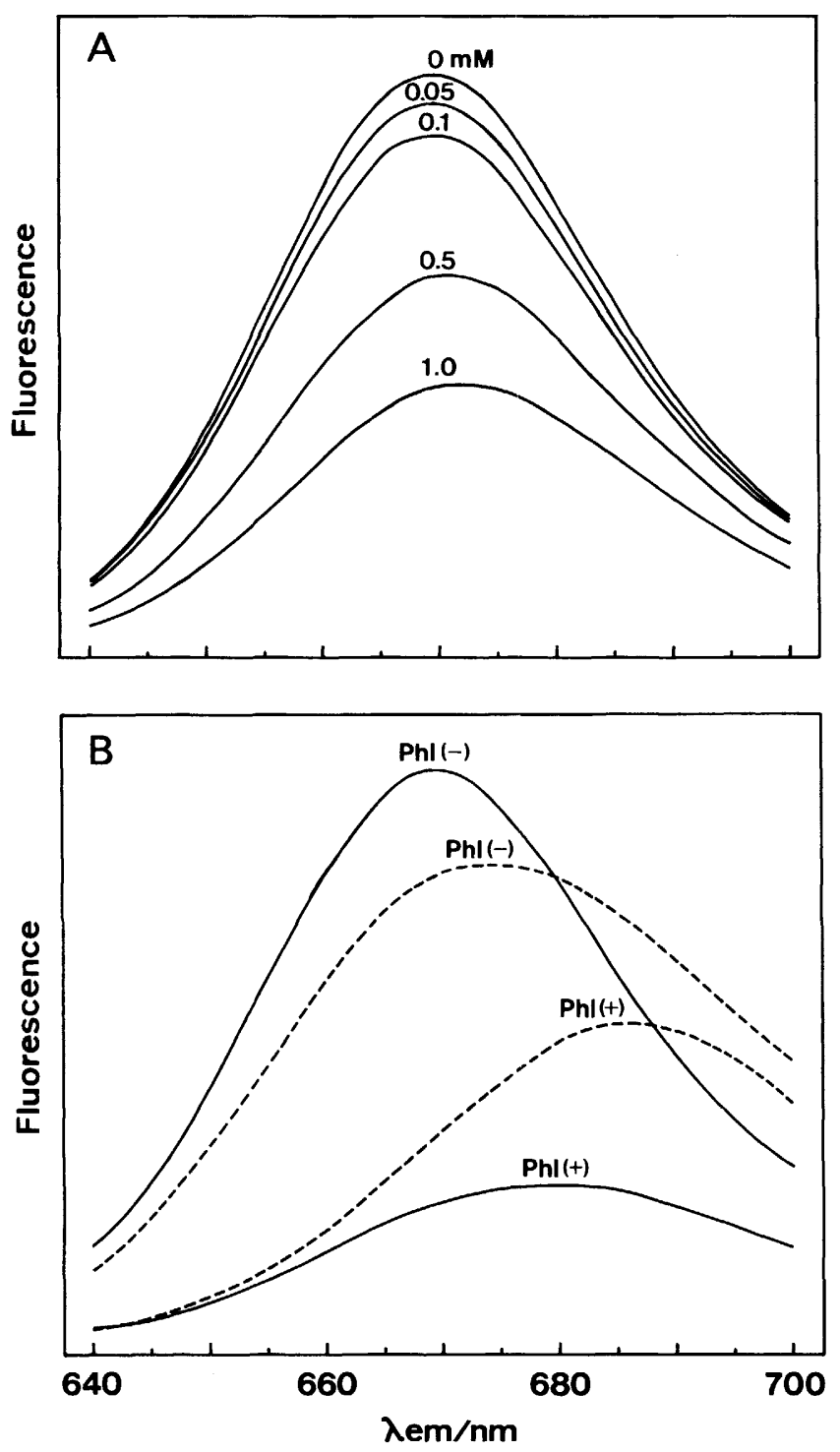

Fig. 6. Effects of phlorizin on the emission spectra of $\operatorname{diS}-\mathrm{C}_{3}(5)$ in the absence (A) and presence (B) of cells. $\lambda_{\mathrm{ex}}=620 \mathrm{~nm}$ (band pass, $5 \mathrm{~nm}$ ). In (B), the cell concentrations

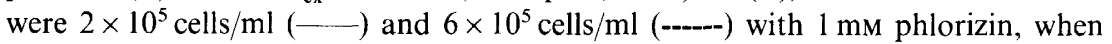
present. 
the assessment of the $\mathrm{pH}$ effect on the sugar-evoked fluorescence responses. The $\mathrm{pH}$ optimum was thus found to be around 7.3, being in good agreement with MAHMOOD et al. (1986) who investigated the rat small intestine.

\section{$\mathrm{Na}^{+}$dependence}

The fluorescence increases due to $2 \mathrm{~mm}$ glucose presented above were obtained in the presence of $121 \mathrm{mM} \mathrm{Na}^{+}$. When the extracellular $\mathrm{Na}^{+}$concentration was reduced to $5.3 \mathrm{~mm}$ by equiosmolal replacement with choline ${ }^{+}$, such changes in fluorescence were suppressed to about one-tenth, on average, of the $\mathscr{F}$-values at $121 \mathrm{~mm} \mathrm{Na}^{+}$. No response was observed in the absence of extracellular $\mathrm{Na}^{+}$.

\section{Inhibition by phlorizin}

Inhibitory concentrations of phlorizin in the suspending medium affected the fluorescence of diS- $\mathrm{C}_{3}(5)$ itself. Figure $6 \mathrm{~A}$ shows the effects of phlorizin on the emission spectra of diS- $\mathrm{C}_{3}(5)$, indicating both quenching and red shift as phlorizin was increased from 0 to $1 \mathrm{~mm}$. Figure $6 \mathrm{~B}$ compares the effects of cell concentration on the phlorizin-induced spectral change. Quenching caused by the same $1 \mathrm{~mm}$ phlorizin was more pronounced in the less concentrated suspension; the extent of red shift was not much different between the two cell concentrations tested. Because of such quenching and red-shift effects, the inhibitory effect of phlorizin on cotransport can be quantitatively described only by using the fractional changes, $\mathscr{F}$. The result thus obtained is shown in Fig. 7. Phlorizin suppressed the glucose-evoked

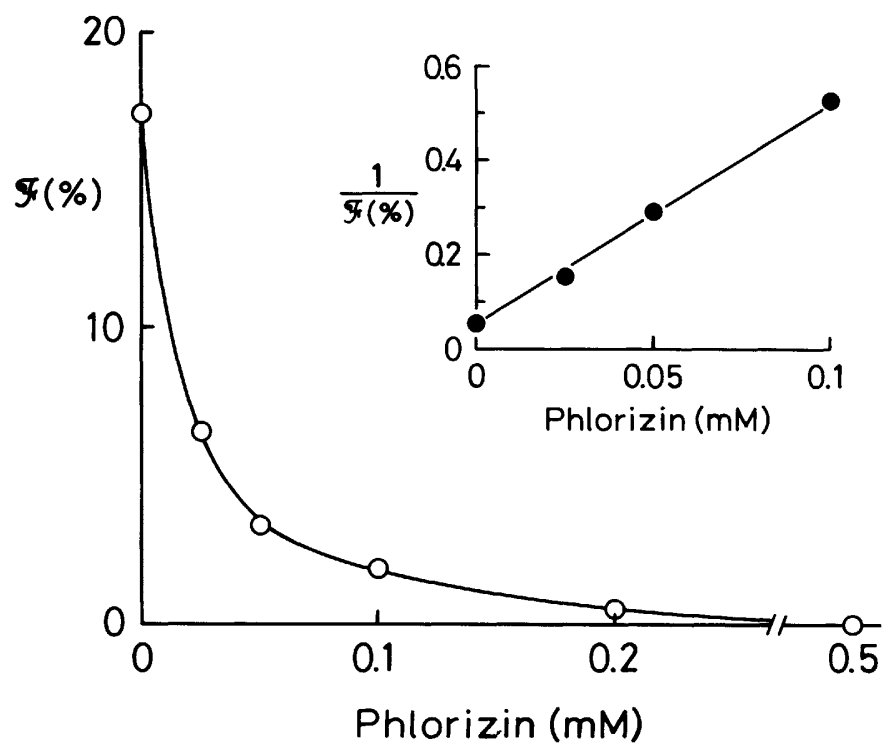

Fig. 7. Dose dependence of phlorizin inhibition. D-Glucose, $2 \mathrm{~mm}$. Inset, Dixon plot of the data at phlorizin $\leq 0.1 \mathrm{~mm}$. 
$\mathscr{F}$, in a dose-dependent manner, with an almost full inhibition at $0.5 \mathrm{~mm}$.

It was necessary to rule out the possibility that phlorizin directly affected the transmembrane partition (and/or binding to membrane) of diS- $\mathrm{C}_{3}(5)$ molecules, which might have resulted in a partial or, most adversely, complete suppression of the final sugar-evoked responses. Accordingly, we examined the effect of phlorizin on fluorescence changes induced by amino acids whose uptake was known to be not inhibited but rather stimulated by phlorizin (TUCKER and КIMMICH, 1973; for a review, see CRANE, 1960). The results obtained from six separate experiments with L-alanine ( $2 \mathrm{~mm}$ ) showed no significant difference in the effect of phlorizin upon $\mathscr{F}$ between the following three concentrations of the glycoside: for $0,0.05$, and $1.0 \mathrm{~mm}$ phlorizin, $\mathscr{F}(\operatorname{mean} \pm$ S.E.M. $)=100,104.8 \pm 5.3(0.2<p<0.5)$, and $103.8 \pm 6.0 \%$ $(0.5<p<0.8)$, respectively. It was thus demonstrated that the present fluoroprobe method can monitor the specific inhibition of sugar cotransport by phlorizin.

As regards the effect of phloretin, no reliable measurements were feasible because phloretin as low as $0.25 \mathrm{~mm}$ gave rise to a prohibitively severe quenching in the dye/cell mixture.

\section{Effects of actively transported sugars}

Several monosaccharides have been shown to be actively transported by the chicken enterocytes (KIMMICH, 1975; КIMmICH and RandLES, 1981). Of these, four sugars were tested and the results are compared in Fig. 8. In the presence of $121 \mathrm{~mm}$ $\mathrm{Na}^{+}$all these sugars gave rise to positive changes in the diS- $\mathrm{C}_{3}(5)$ fluorescence indicative of depolarization of membrane potentials. With $2 \mathrm{~mm}$ test sugars, the response to D-glucose was greatest, giving an $\mathscr{F}$-value of about 0.2 ; the responses to the rest of the sugars relative to D-glucose were $88 \%$ for D-galactose, $85 \%$ for $\alpha$ methyl-D-glucoside, and $81 \%$ for 3-O-methyl-D-glucose. The cells kept in medium C at $0^{\circ} \mathrm{C}$ for one day showed no such responses. All these fluorescence increases were phlorizin inhibitable. No positive responses were detected with $2 \mathrm{~mm}$ L-glucose,

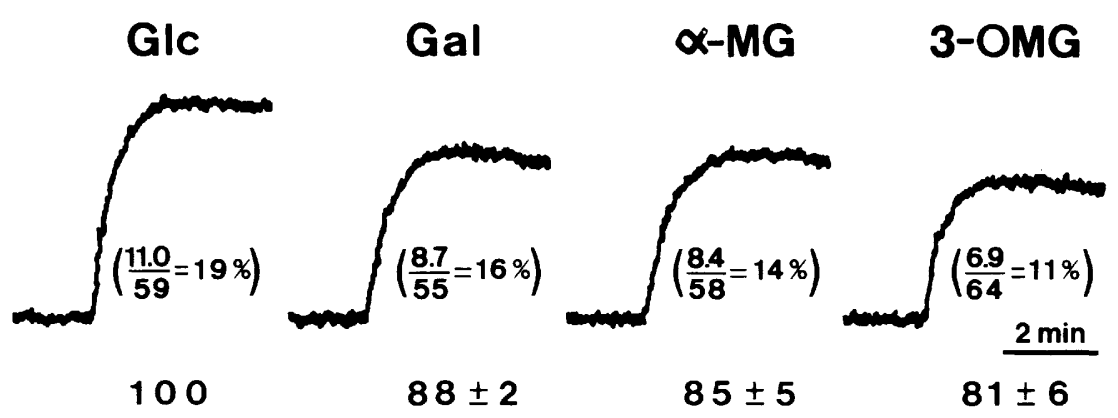

Fig. 8. Comparison of 4 monosaccharides $(2 \mathrm{~mm})$ with regard to their potency to increase the difference-mode fluorescence. For these recordings, a single batch of cells was used. Values in parentheses, $\mathscr{F}\left(=\Delta F / F_{0}\right)$ in $\%$. Values at the bottom, relative potency expressed as mean \pm S.E.M. from 10 separate experiments. 
which has been reported to be accumulated actively but with a very low affinity $\left(K_{\mathrm{t}} \simeq 65 \mathrm{~mm}\right)($ CASPARY and CRANE, 1968).

No responses to D-fructose or 2-deoxy-D-glucose

D-Fructose, a ketohexose known to be transported passively via a $\mathrm{Na}^{+}$. independent mechanism (WILSON and VINCENT, 1955; BARRY et al., 1964; SCHULTZ and STRECKER, 1970; KIMMICH and RandLES, 1975), did not induce any detectable responses when added at a concentration of $2 \mathrm{~mm}$. When increased up to $10 \mathrm{~mm}$, however, this sugar occasionally caused a barely detectable increase in fluorescence, which could be accounted for by a trace amount of D-glucose as contaminant (about $0.04 \%$ in molar ratio) contained in the sugar lot as received.

Another sugar, 2-deoxy-D-glucose, which also is transported in a $\mathrm{Na}^{+}$independent manner (WILSON and LANDAU, 1960; BARRY et al., 1964; GoLDNER et al., 1969; КіммісH and RandLES, 1975, 1976) was tested. When chromatographically purified 2-deoxyglucose was applied, no positive responses were observed for sugar concentrations up to $10 \mathrm{~mm}$. However, at the highest concentration used $(10 \mathrm{~mm})$, weak responses $(\mathscr{F} \leq 0.003)$ were occasionally detectable even when the "purified" sugar was applied. These responses were fully abolished by $0.5 \mathrm{~mm}$ phlorizin (not shown) and therefore most likely attributed to the contaminant glucose that escaped the chromatographic purification. In fact, thin-layer chromatography of the "purified" 2-deoxyglucose revealed a contamination by D-glucose which was below $0.02 \%$ in molar ratio.

\section{Disaccharide-evoked fluorescence changes}

Several disaccharides were surveyed for their potency to evoke any fluorescence changes. Maltose, among those tested, gave rise to a sizable increase in fluorescence, accounting for about $40 \%$ of the D-glucose-evoked $\mathscr{F}$, which was $\mathrm{Na}^{+}$dependent

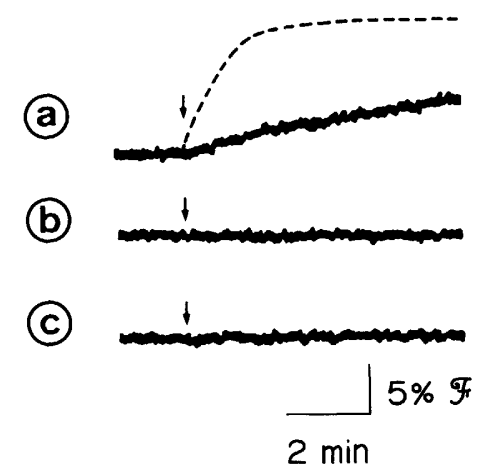

Fig. 9. $\mathrm{Na}^{+}$dependence and phlorizin inhibition of maltose-evoked fluorescence changes. Maltose $(2 \mathrm{mM})$ or D-glucose $(2 \mathrm{mM}$, broken line) was added to cell suspensions at the time indicated by arrows. (a) $121 \mathrm{mM} \mathrm{Na}^{+}$(medium C), (b) $5.3 \mathrm{mM} \mathrm{Na}^{+}$, (c) $121 \mathrm{mM} \mathrm{Na}^{+}$plus $1 \mathrm{~mm}$ phlorizin. 


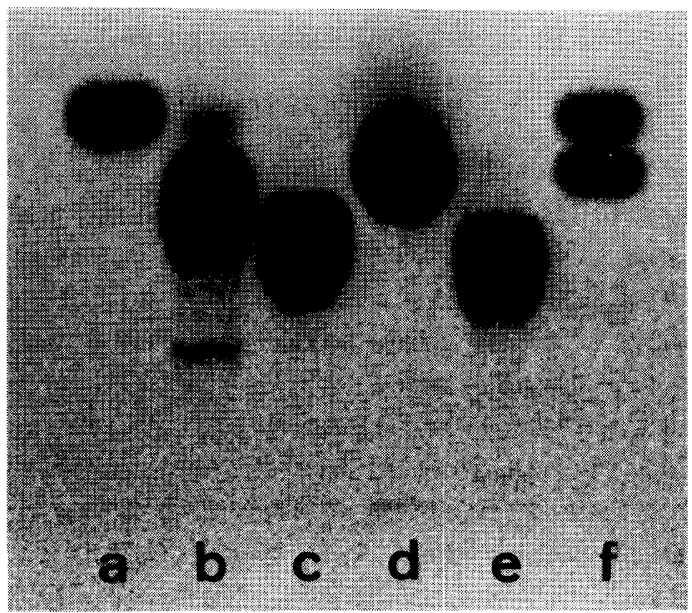

Fig. 10. Thin-layer chromatogram of the disaccharides tested. Lanes: a, D-glucose $(0.2 \mathrm{mmol}) ; \mathrm{b}$, maltose $(1 \mathrm{mmol})$; $\mathrm{c}$, trehalose $(1 \mathrm{mmol})$; $\mathrm{d}$, sucrose $(1 \mathrm{mmol})$; e, lactose $(0.8 \mathrm{mmol})$; $\mathrm{f}$, D-glucose $(0.05 \mathrm{mmol})$ plus D-galactose $(0.05 \mathrm{mmol})$.

and phlorizin sensitive as well (Fig. 9). The maltose lot tested was also contaminated by a trace amount (about $0.5 \%$ in molar ratio) of D-glucose (Fig. 10, lane b); however, this amount alone was unlikely to explain the observed size of the fluorescence response to maltose because preliminary experiments showed that $0.01 \mathrm{mM} \mathrm{D}$-glucose (corresponding to the final concentration of the contaminant) evoked $\mathscr{F}$ which was lower than $10 \%$ of that evoked by $2 \mathrm{~mm}$ glucose. Our tentative interpretation is that, via a membrane-associated maltase system, the added maltose was hydrolyzed to the constituent D-glucose (GRAY, 1981), which, in turn, induced the fluorescence increase. Other disaccharides tested, i.e., lactose, sucrose, and trehalose (all in $2 \mathrm{~mm}$ ), evoked no, or barely detectable, fluorescence increases. Such an observation appears to indicate the loss of the corresponding disaccharidases during preparation or the inherently low activities of these enzymes in the small intestine of chickens.

\section{Concluding remarks}

We have defined, for the first time, the experimental conditions whereby carbocyanines can be utilized with isolated enterocytes to detect cotransport-related changes in membrane potential, if due precautions are taken against cell deterioration and baseline shift. Our results show that the sugar-evoked fluorescence changes indicative of depolarization of membrane potentials share all the features typical of the $\mathrm{Na}^{+}$/sugar cotransport in the intestinal epithelial cells, such as substrate specificity, sodium dependence and phlorizin inhibition. These results also show that the fluoroprobe technique as applied to isolated, normally energized cells will be useful for the characterization of cotransport-associated cellular responses at the whole cell level. 
We thank Dr. George A. Kimmich (University of Rochester, NY), Dr. K. Asami, Dr. M. Ogawa, and Dr. T. Taniguchi for helpful suggestions, and Mrs. T. Ichinowatari for technical assistance. Thanks are also due to Dr. Steven Emmet (University of California, San Diego, CA) for reading the manuscript. This work was supported in part by a Grant-in-Aid for Scientific Research from the Ministry of Education, Science and Culture, Japan.

\section{REFERENCES}

Barry, R. J. C., Dikstein, S., Matthews, J., Smyth, D. H., and Wright, E. M. (1964) Electrical potentials associated with intestinal sugar transport. J. Physiol. (Lond.), 171: 316-338.

CASPARY, W. F. and Crane, R. K. (1968) Inclusion of L-glucose within the specificity limits of the active sugar transport system of hamster small intestine. Biochim. Biophys. Acta, 163: $395-400$.

Cheeseman, C. I. and Devlin, D. (1985) The effect of amino acids and dipeptides on sodium-ion transport in rat enterocytes. Biochim. Biophys. Acta, 812: 767-773.

Clarkson, T. W., Cross, A. C., and Toole, S. (1961) Dependence on substrate of the electrical potential across the isolated gut. Nature (Lond.), 191: 501-502.

Cohen, L. B. and SAlzberg, B. M. (1978) Optical measurement of membrane potential. Rev. Physiol. Biochem. Pharmacol., 83: 35-88.

Crane, R. K. (1960) Intestinal absorption of sugars. Physiol. Rev., 40: 789-825.

Freedman, J. C. and LARIS, P. C. (1981) Electrophysiology of cells and organelles: Studies with optical potentiometric indicators. Int. Rev. Cytol., Suppl. 12: 177-246.

Frizzel, R. A. and SCHUltz, S. G. (1972) Ionic conductances of extracellular shunt pathway in rabbit ileum. Influence of shunt on transmural sodium transport and electrical potential differences. J. Gen. Physiol., 59: 318-346.

Goldner, A. M., HaJjar, J. J., and Curran, P. F. (1969) 2-Deoxyglucose transfer in rabbit intestine. Biochim. Biophys. Acta, 173: 572-574.

Gray, G. M. (1981) Carbohydrate absorption and malabsorption. In: Physiology of the Gastrointestinal Tract, ed. by Johnson, L. R., Raven Press, New York, pp. 1063-1072.

HARTREE, E. F. (1972) Determination of protein: A modification of the Lowry method that gives a linear photometric response. Anal. Biochem., 48: 422-427.

HLADKY, S. B. and RINK, T. J. (1976) Potential difference and the distribution of ions across the human red blood cell membrane: A study of the mechanism by which the fluorescent cation, diS- $\mathrm{C}_{3}-(5)$ reports membrane potential. J. Physiol. (Lond.), 263: 287-319.

Hoffman, J. F. and Laris, P. C. (1974) Determination of membrane potentials in human and Amphiuma red blood cells by means of a fluorescent probe. J. Physiol. (Lond.), 239: 519-552.

Hoshi, T. and Komatsu, Y. (1968) Sugar-evoked potential in isolated toad intestine. Jpn. J. Physiol., 18: 508-519.

Кіммісн, G. A. (1975) Preparation and characterization of isolated intestinal epithelial cells and their use in studying intestinal transport. In: Methods in Membrane Biology, ed. by Korn, 'E. D., Plenum Press, New York, Vol. 4, pp. 51-115.

Kimmich, G. A. (1981) Intestinal absorption of sugar. In: Physiology of the Gastrointestinal Tract, ed. by Johnson, L. R., Raven Press, New York, pp. 1035-1061.

KimmiCh, G. A. and Randles, J. (1975) $\mathrm{A} \mathrm{Na}^{+}$-independent, phloretin-sensitive monosaccharide transport system in isolated intestinal epithelial cells. J. Membr. Biol., 23: 5776. 
Kimmich, G. A. and RandeEs, J. (1976) 2-Deoxyglucose transport by intestinal epithelial cells isolated from the chick. J. Membr. Biol., 27: 363-379.

Kimmich, G. A. and RandLES, J. (1979) Energetics of sugar transport by isolated intestinal epithelial cells: Effects of cytochalasin B. Am. J. Physiol, 237: C56-C63.

Kimmich, G. A. and RandLes, J. (1981) $\alpha$-Methylglucoside satisfies only $\mathrm{Na}^{+}$-dependent transport system of intestinal epithelium. Am. J. Physiol., 241: C227-C232.

Lyon, I. and Crane, R. K. (1966) Studies on transmural potentials in vitro in relation to intestinal absorption. I. Apparent Michaelis constants for $\mathrm{Na}^{+}$-dependent sugar transport. Biochim. Biophys. Acta, 112: 278-291.

Mahmood, A., Sharma, K. K., Mahmood, S., and Dani, H. M. (1986) Effect of pH on sodium-stimulated D-glucose uptake in rat small intestine. Indian J. Biochem. Biophys., 23: $212-214$.

OKadA, Y., IrimaJiRI, A., and InOUYe, A. (1977a) Electrical properties and active solute transport in rat small intestine. II. Conductive properties of transepithelial routes. $J$. Membr. Biol., 31: 221-232.

OKada, Y., TsuchiYa, W., Irimajiri, A., and INOUYE, A. (1977b) Electrical properties and active solute transport in rat small intestine. I. Potential profile changes associated with sugar and amino acid transports. J. Membr. Biol., 31: 205-219.

Phillips, H. J. (1973) Dye exclusion tests for cell viability. In: Tissue Culture. Methods and Applications, ed. by Kruse, P. F., Jr. and Patterson, M. K., Jr., Academic Press, New York, pp. 406-408.

Rose, R. C. and Schultz, S. G. (1971) Studies on the electrical potential profile across rabbit ileum. Effects of sugars and amino acids on transmural and transmucosal electrical potential differences. J. Gen. Physiol., 57: 639-663.

Schultz, S. G. (1979) Transport across small intestine. In: Membrane Transport in Biology, ed. by Giebisch, G., Tosteson, D. C., and Ussing, H. H., Springer-Verlag, New York, Vol. IV B, pp. 749-780.

SCHultZ, S. G. (1981) Salt and water absorption by mammalian small intestine. In: Physiology of the Gastrointestinal Tract, ed. by JoHnson, L. R., Raven Press, New York, pp. 983-989.

Schultz, S. G. and Strecker, C. K. (1970) Fructose influx across the brush border of rabbit ileum. Biochim. Biophys. Acta, 211: 586-588.

Schultz, S. G. and Zalusky, R. (1964) Ion transport in isolated rabbit ileum. I. Shortcircuit current and Na fluxes. J. Gen. Physiol., 47: 567-584.

Sims, P. J., Waggoner, A. S., Wang, C.-H., and Hoffman, J. F. (1974) Studies on the mechanism by which cyanine dyes measure membrane potential in red blood cells and phosphatidylcholine vesicles. Biochemistry, 13: 3315-3330.

Taniguchi, T., Hirata, F., and Hayaishi, O. (1977) Intracellular utilization of superoxide anion by indoleamine 2,3-dioxygenase of rabbit enterocytes. J. Biol. Chem., 252: 2774 2776.

TsuchiYA, W. and OKADA, Y. (1982) Membrane potential changes associated with differentiation of enterocytes in the rat intestinal villi in culture. Devel. Biol., 94: 284 290.

Tsuchiya, W., Okada, Y., and Inouye, A. (1980) Membrane potential measurements in cultured intestinal villi. Membr. Biochem., 3: 147-153.

TUCKeR, A. M. and Kiмmich, G. A. (1973) Characteristics of amino acid accumulation by isolated intestinal epithelial cells. J. Membr. Biol., 12: 1-22.

WagGoner, A. S. (1979) Dye indicators of membrane potential. Annu. Rev. Biophys. Bioeng., 8: 47-68. 
Watford, M., LUND, P., and KreBs, H. A. (1979) Isolation and metabolic characteristics of rat and chicken enterocytes. Biochem. J., 178: 589-596.

White, J. F. and Armstrong, W. McD. (1971) Effect of transported solutes on membrane potentials in bullfrog small intestine. Am. J. Physiol., 221: 194-201.

WiLSON, T. H. and LANDAU, B. R. (1960) Specificity of sugar transport by the intestine of the hamster. Am. J. Physiol., 198: 99-102.

WiLSON, T. H. and VINCENT, T. N. (1955) Absorption of sugars in vitro by the intestine of the golden hamster. J. Biol. Chem., 216: 851-866.

Wright, E. M. (1984) Electrophysiology of plasma membrane vesicles. Am. J. Physiol., 246: F363-F372. 